\title{
Expression of MMP-2 and TIMP-1 in cerebrospinal fluid and the correlation with dynamic changes of serum PCT in neonatal purulent meningitis
}

\author{
HUILAN CHEN*, FEI WU*, RONG FU and XIANGCHUN FENG \\ Department of Neonatology, Qingdao Women and Children Hospital, Qingdao, Shandong 266034, P.R. China
}

Received July 14, 2017; Accepted November 1, 2017

DOI: $10.3892 /$ etm. 2017.5543

\begin{abstract}
Matrix metalloproteinase 2 (MMP-2) and tissue inhibitor of metalloproteinase-1 (TIMP-1) levels in cerebrospinal fluid of pediatric patients with neonatal purulent meningitis were observed to analyze changes in serum procalcitonin (PCT) and the correlation among the three factors (MMP-2, TIMP-1 and PCT). Sixty pediatric patients with neonatal purulent meningitis from April 2015 to December 2016 were enrolled as the purulent meningitis group and 60 pediatric patients with viral encephalitis treated during the same period were enrolled as the viral encephalitis group. Additionally, 60 healthy newborns who underwent physical examinations in our hospital during the same period were enrolled as the control group. The levels of MMP-2 were $136.73 \pm 25.42 \mathrm{ng} / \mathrm{ml}$ in the purulent meningitis group, $45.32 \pm 6.57 \mathrm{ng} / \mathrm{ml}$ in the viral encephalitis group and $1.32 \pm 0.51 \mathrm{ng} / \mathrm{ml}$ in the control group and the differences between the three groups were statistically significant $(\mathrm{F}=15.052, \mathrm{p}<0.05)$. The levels of TIMP-1 in cerebrospinal fluid were $374.55 \pm 36.04 \mathrm{ng} / \mathrm{ml}$ in the purulent meningitis group, $176.61 \pm 21.06 \mathrm{ng} / \mathrm{ml}$ in the viral encephalitis group and $7.72 \pm 2.44 \mathrm{ng} / \mathrm{ml}$ in the control group. The serum levels of PCT were $14.56 \pm 2.21 \mathrm{ng} / \mathrm{ml}$ in the purulent meningitis group, $9.04 \pm 1.17 \mathrm{ng} / \mathrm{ml}$ in the viral encephalitis group and $0.38 \pm 0.14 \mathrm{ng} / \mathrm{ml}$ in the control group. The level of MMP-2 in cerebrospinal fluid of pediatric patients in the purulent meningitis group was positively correlated with the level of serum PCT ( $r=0.582, p<0.05)$; the level of TIMP-1 in cerebrospinal fluid of pediatric patients in the viral encephalitis group was positively correlated with the level of serum PCT $(r=0.635$, $\mathrm{p}<0.05$ ). In conclusion, MMP-2 and TIMP-1 were positively
\end{abstract}

Correspondence to: Dr Xiangchun Feng, Department of Neonatology, Qingdao Women and Children Hospital, 6 Tongfu Road, Shibei, Qingdao, Shandong 266034, P.R. China

E-mail: fengxiangchun1234@126.com

*Contributed equally

Key words: newborns, purulent meningitis, MMP-2, TIMP-1, procalcitonin correlated with the levels of serum PCT, suggesting that MMP-2, TIMP-1 and PCT were involved in the occurrence and development of neonatal purulent meningitis.

\section{Introduction}

Neonatal purulent meningitis is a common infection of the central nervous system in pediatric patients. Early diagnosis is difficult and disease is associated with a high disability rate and severely affects the lives and heath of children. Both purulent meningitis and viral encephalitis are major pediatric central nervous system infections (1-3). At present, the gold standard for clinical diagnosis of purulent meningitis and viral encephalitis is etiological examination of cerebrospinal fluid, although this form of examination is not optimal. It has limitations such as low positive rate of bacterial culture, and time-consuming procedure, which have restricted its clinical application $(4,5)$. Therefore, it is necessary to study new methods for the diagnosis of purulent meningitis and viral encephalitis. Matrix metalloproteinase 2 (MMP-2), tissue inhibitor of metalloproteinase-1 (TIMP-1) and procalcitonin (PCT) are important factors that have been the focus of many studies in recent years. It has been shown that MMP-2, TIMP-1 and PCT may be involved in the development of central nervous system infections (6). At present, there are few studies on MMP-2, TIMP-1 and PCT in the clinical diagnosis and treatment of neonatal purulent meningitis. The aim of the present study was to determine the significance of MMP-2 and TIMP-1 expression in cerebrospinal fluid and their correlation with dynamic changes of serum PCT in patients with neonatal purulent meningitis, to provide a theoretical basis for the clinical diagnosis and treatment of neonatal purulent meningitis.

\section{Patients and methods}

Patients. Sixty pediatric patients with neonatal purulent meningitis who underwent treatment in Qingdao Women and Children Hospital from April 2015 to December 2016 were enrolled as the purulent meningitis group. There were 40 males and 20 females. Gestational age was 38-42 weeks, admission age was $2 \mathrm{~h}$ to 25 days and admission weight was $2.6-4.2 \mathrm{~kg}$. All patients in this group conformed to the diagnostic standards of purulent meningitis, and other diseases were excluded. 
Simultaneously, 60 pediatric patients with viral encephalitis treated in our hospital during the same period were enrolled as the viral encephalitis group. There were 39 males and 21 females. Gestational age was 38-42 weeks, admission age was $1 \mathrm{~h}$ to 24 days and admission weight was $2.5-4.3 \mathrm{~kg}$. All patients in this group conformed to the diagnostic standards of viral encephalitis, and other diseases were excluded. Sixty healthy newborns who underwent physical examinations in our hospital during the same period were enrolled as the control group. There were 39 males and 21 females. Gestational age was 38-42 weeks, admission age was $1 \mathrm{~h}$ to 26 days and admission weight was $2.5-4.1 \mathrm{~kg}$. There were no significant differences in general parameters such as sex, gestational age or admission weight of patients between the three groups. The study was approved by the Ethics Committee of Qingdao Women and Children Hospital and informed consents were signed by the patients' parents.

Methods. Cerebrospinal fluid and venous blood samples were collected from the purulent meningitis group and viral encephalitis group within several hours following admission in the acute stage. Cerebrospinal fluid and venous blood samples were collected from the control group at the time of physical examination. All samples were maintained at $-70^{\circ} \mathrm{C}$ until use.

The levels of MMP-2 and TIMP-1 in cerebrospinal fluid were measured by enzyme-linked immunosorbent assay (ELISA). ELISA kits for human MMP-2 and TIMP-1 were from Nanjing Letter Sail Biotechnology Co., Ltd. (Nanjing, China) and used according to the manufacturer's instructions. A chemiluminescent analyzer (DiaSorin Deutschland $\mathrm{GmbH}$, Dietzenbach, Germany) and matching R\&D kits (R\&D Systems, Minneapolis, MN, USA) were used to measure the levels of PCT.

Observational indexes. The levels of MMP-2 and TIMP-1 in cerebrospinal fluid and serum PCT levels were compared and the correlation among the above indexes for pediatric patients with neonatal purulent meningitis was analyzed.

Statistical analysis. SPSS 20.0 software (IBM, Armonk, NY, USA) was used for statistical analyses. The F-test was used for comparisons among the three groups; correlation analyses adopted the relevant Spearman's test with the test level $\alpha=0.05$.

\section{Results}

Comparison of MMP-2 levels in cerebrospinal fluid. The levels of MMP-2 in cerebrospinal fluid of pediatric patients in the purulent meningitis group were $136.73 \pm 25.42 \mathrm{ng} / \mathrm{ml}$, those in the viral encephalitis group were $45.32 \pm 6.57 \mathrm{ng} / \mathrm{ml}$ and those in the control group were $1.32 \pm 0.51 \mathrm{ng} / \mathrm{ml}$. The differences between the three groups were statistically significant $(\mathrm{F}=15.052$, $\mathrm{p}<0.05)$ (Fig. 1).

Comparison of TIMP-1 levels in cerebrospinal fluid. The levels of TIMP-1 in cerebrospinal fluid of pediatric patients in the purulent meningitis group were $374.55 \pm 36.04 \mathrm{ng} / \mathrm{ml}$, those in the viral encephalitis group were $176.61 \pm 21.06 \mathrm{ng} /$ $\mathrm{ml}$ and those in the control group were $7.72 \pm 2.44 \mathrm{ng} / \mathrm{ml}$.

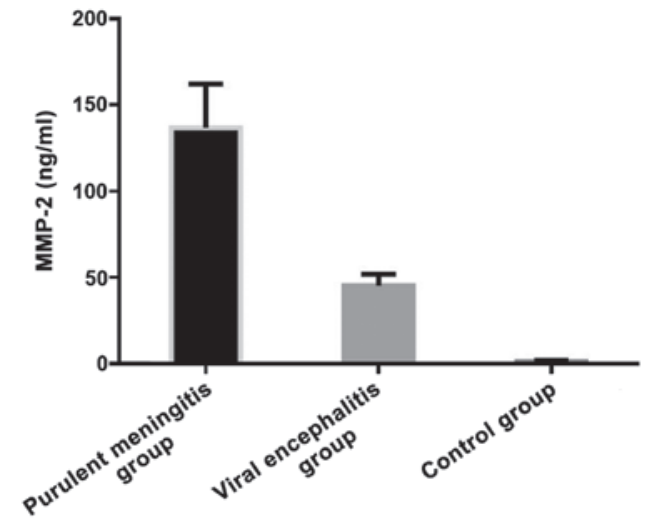

Figure 1. Comparison of MMP-2 levels in cerebrospinal fluid of pediatric patients. MMP-2, matrix metalloproteinase 2.

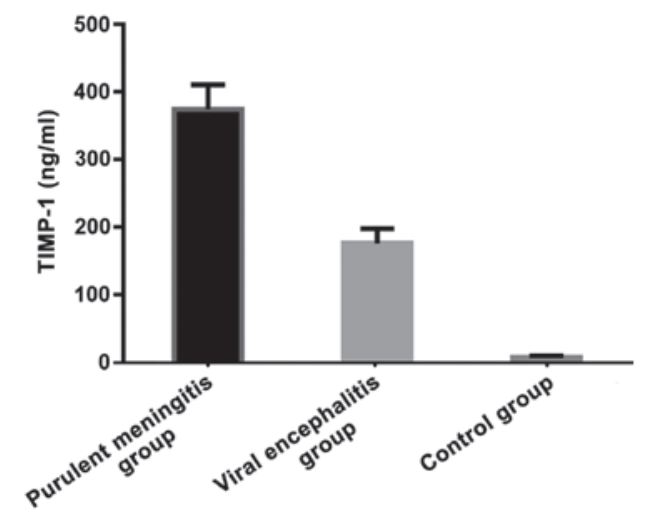

Figure 2. Comparisons of TIMP-1 levels in cerebrospinal fluid of pediatric patients. TIMP-1, tissue inhibitor of metalloproteinase-1.

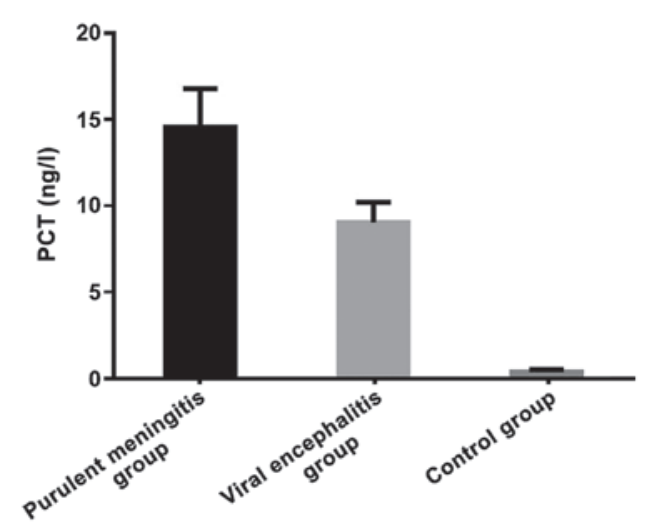

Figure 3. Comparison of serum PCT levels in pediatric patients. PCT, procalcitonin.

The differences between the three groups were statistically significant $(\mathrm{F}=16.738, \mathrm{p}<0.05)$ (Fig. 2).

Comparison of PCT levels in the serum of pediatric patients. The serum levels of PCT in pediatric patients in the purulent meningitis group were $14.56 \pm 2.21 \mathrm{ng} / \mathrm{ml}$, those in the viral encephalitis group were $9.04 \pm 1.17 \mathrm{ng} / \mathrm{ml}$ and those in the control group were $0.38 \pm 0.14 \mathrm{ng} / \mathrm{ml}$. The differences between the three groups were statistically significant $(F=13.664$, $\mathrm{p}<0.05$ ) (Fig. 3). 


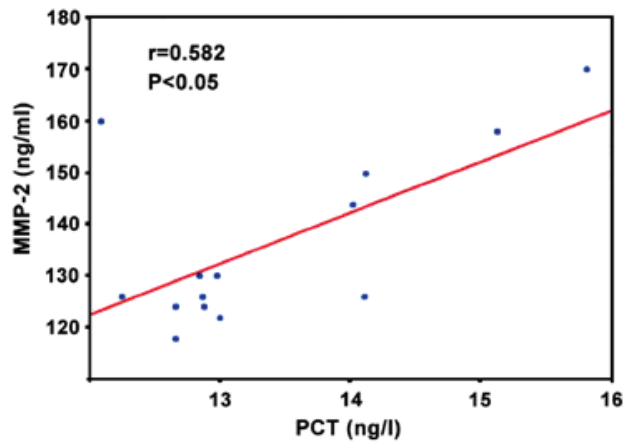

Figure 4. The MMP-2 level in cerebrospinal fluid of pediatric patients in the purulent meningitis group was positively correlated with the level of serum PCT. MMP-2, matrix metalloproteinase 2; PCT, procalcitonin.

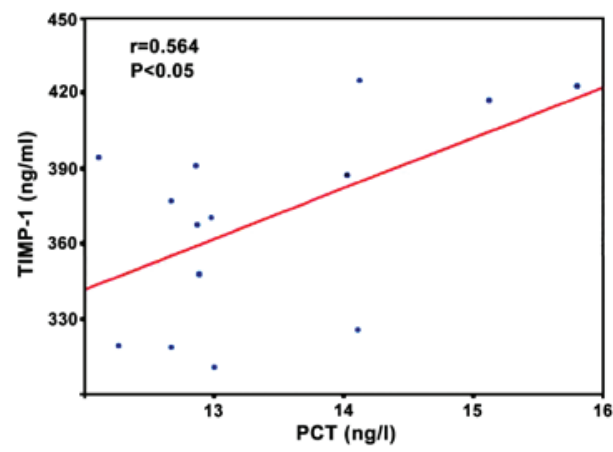

Figure 5. The level of TIMP-1 in cerebrospinal fluid of pediatric patients in the purulent meningitis group was positively correlated with the level of serum PCT. TIMP-1, tissue inhibitor of metalloproteinase-1; PCT, procalcitonin.

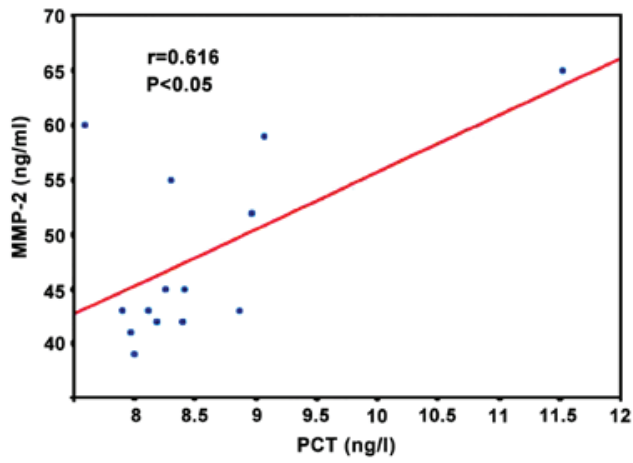

Figure 6. The level of MMP-2 in cerebrospinal fluid of pediatric patients in the viral encephalitis group was positively correlated with the level of serum PCT. MMP-2, matrix metalloproteinase 2; PCT, procalcitonin.

Correlation analysis in the purulent meningitis group. The level of MMP-2 in cerebrospinal fluid of pediatric patients in the purulent meningitis group was positively correlated with the level of serum PCT $(r=0.582, \mathrm{p}<0.05)$ (Fig. 4). Furthermore, the level of TIMP-1 in cerebrospinal fluid of pediatric patients in the purulent meningitis group was positively correlated with the level of serum PCT $(r=0.564$, p<0.05) (Fig. 5).

Correlation analysis in the viral encephalitis group. The level of MMP-2 in cerebrospinal fluid of pediatric patients in the

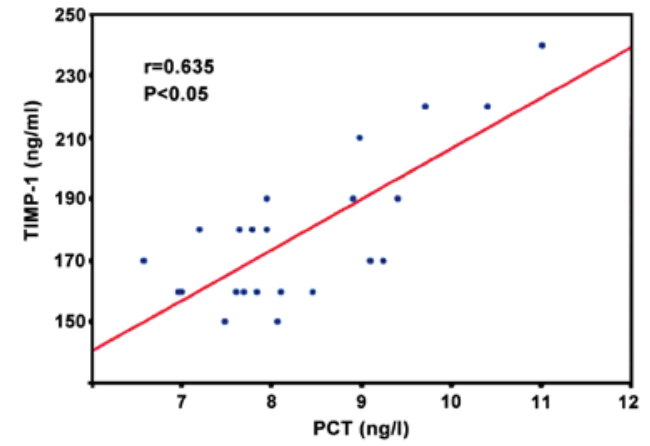

Figure 7. The level of TIMP-1 in cerebrospinal fluid of pediatric patients in the viral encephalitis group was positively correlated with the level of serum PCT. TIMP-1, tissue inhibitor of metalloproteinase-1; PCT, procalcitonin.

viral encephalitis group was positively correlated with the level of serum PCT $(r=0.616, \mathrm{p}<0.05)$ (Fig. 6). Furthermore, the level of TIMP-1 in cerebrospinal fluid of pediatric patients in the viral encephalitis group was positively correlated with the level of serum PCT ( $r=0.635, p<0.05)$ (Fig. 7).

\section{Discussion}

When newborns suffer from purulent meningitis, severe disease conditions can lead to death. However, even cases who survive may experience sequelae (7-10) such as slow development of the nervous system, visual impairment and hydrocephalus. A previous study showed that (11) neonatal purulent meningitis is an inflammatory reaction caused by the combined action of pathogenic bacteria and inflammatory factors. In recent years, clinical application of antibiotics has become more extensive, which leads to atypia in examinations of cerebrospinal fluid in patients with purulent meningitis. In particular, the clinical manifestations of neonatal purulent meningitis are more atypical $(4,12,13)$. This also adds difficulty to the clinical identification of purulent meningitis and viral encephalitis.

Previously, it was shown that MMPs are closely related to central nervous system infections, possibly because MMPs can degrade type IV collagen of the basement membrane of blood vessels, destroying the blood-brain barrier, which allows $\mathrm{T}$ cells to smoothly pass through the blood-brain barrier to reach the central nervous system and actively participate in inflammation (14). MMP-2 plays a highly important role in central nervous system infections and participates in blood-brain barrier damage and immunological pathogenesis. The results of this study showed that the differences in the levels of MMP-2 in cerebrospinal fluid in patients in the purulent meningitis group, viral encephalitis group and control group were statistically significant $(\mathrm{p}<0.05)$ and the levels of MMP-2 in the purulent meningitis group were higher than those in the viral encephalitis group and control group. These data indicate that MMP-2 is highly expressed in neonatal cerebrospinal fluid and $\mathrm{T}$ lymphocytes and many other inflammatory cells are induced to smoothly pass through the blood-brain barrier and enter the central nervous system, which contributes to the pathogenesis of neonatal purulent meningitis.

The expression of TIMP-1 is low in humans. However, once inflammation occurs, the level of TIMP-1 is highly increased $(15,16)$. The results of this study were consistent 
with these observations. The levels of TIMP-1 in cerebrospinal fluid of pediatric patients in the purulent meningitis group were higher than those in the viral encephalitis group and control group and the differences between the three groups were statistically significant $(\mathrm{p}<0.05)$. These results were consistent with previous research (16).

PCT is a newly identified inflammatory factor and is often used in the clinical diagnosis of infectious diseases. Under normal conditions, the serum levels of PCT are low in humans, and PCT is mainly generated by thyroid C cells (17-19). Under the conditions of bacterial infection, liver macrophages and pulmonary lymphocytes synthesize and secrete PCT, which increase serum levels of PCT. Relevant studies showed that PCT has a certain application value in the clinical diagnosis of neonatal septicemia (20). The results of this study showed that the levels of PCT in the serum of pediatric patients in the purulent meningitis group were higher than those in the viral encephalitis group and control group and the differences between the three groups were statistically significant $(\mathrm{p}<0.05)$. These data suggest that inflammation can stimulate the secretion of PCT. Therefore, the levels of PCT in serum of pediatric patients with neonatal purulent meningitis were significantly higher than those with viral encephalitis or healthy newborns. Additionally, the changes in serum PCT levels can reflect the conditions of neonatal infection and meningitis.

Further analysis showed that the levels of MMP-2 in cerebrospinal fluid of pediatric patients in the purulent meningitis group were positively correlated with the levels of serum PCT $(r=0.582, p<0.05)$ and the levels of TIMP-1 in cerebrospinal fluid of pediatric patients in the purulent meningitis group were positively correlated with the levels of serum PCT $(r=0.564, p<0.05)$; the levels of MMP-2 in cerebrospinal fluid of pediatric patients in the viral encephalitis group were positively correlated with the levels of serum PCT $(\mathrm{r}=0.616, \mathrm{p}<0.05)$ and the levels of TIMP-1 in cerebrospinal fluid of pediatric patients in the viral encephalitis group were positively correlated with the levels of serum PCT $(r=0.635$, $\mathrm{p}<0.05)$. These data suggest that MMP-2 and TIMP-1 in cerebrospinal fluid, as well as serum PCT, participate in the occurrence and development of neonatal purulent meningitis and viral encephalitis and are positively correlated with each other. Therefore, the joint detection and synthetic judgment for MMP-2 and TIMP-1 in cerebrospinal fluid and serum PCT have important application value in the differential diagnosis of neonatal purulent meningitis and viral encephalitis and are worth recommending widely.

\section{References}

1. Dhahir Al-Mendalawi M: Utility of cerebrospinal fluid cortisol level in acute bacterial meningitis. Ann Indian Acad Neurol 18: 491-492, 2015.

2. Srinivasan L, Kilpatrick L, Shah SS, AbbasiS and Harris MC: Cerebrospinal fluid cytokines in the diagnosis of bacterial meningitis in infants. Pediatr Res 80: 566-572, 2016.

3. Lee J, Kwon H, Lee JS, Kim HD and Kang HC: Applying the bacterial meningitis score in children with cerebrospinal fluid pleocytosis: A single center's experience. Korean J Pediatr 58: 251-255, 2015.
4. Roine I, Pelkonen T, Lauhio A, Lappalainen M, Cruzeiro ML, Bernardino L, Tervahartiala T, Sorsa T and Peltola H: Changes in MMP-9 and TIMP-1 concentrations in cerebrospinal fluid after 1 week of treatment of childhood bacterial meningitis. J Clin Microbiol 53: 2340-2342, 2015.

5. Xiao X, Zhang Y,Zhang L, Kang P and Ji N: The diagnostic value of cerebrospinal fluid lactate for post-neurosurgical bacterial meningitis: A meta-analysis. BMC Infect Dis 16: 483, 2016.

6. Hashim IA, Walsh A, Hart CA and Shenkin A: Cerebrospinal fluid interleukin- 6 and its diagnostic value in the investigation of meningitis. Ann Clin Biochem 32: 289-296, 1995.

7. Agossou J, Adédémy JD, Noudamadjo A, Houessou MRM, Tsawlassou P, Assogba R, Sagbo GG, Lalya HF, Alao MJ, Bankolé $\mathrm{H}$, et al: Serotypes of bacteria encountered in childhood purulent meningitis in children in Parakou (Benin) in 2011. Open J Pediatr 06: 109-119, 2016.

8. Kamoun F, Dowlut MB, Ameur SB, Sfaihi L, Mezghani S, Chabchoub I, Hammami A, Aloulou $\mathrm{H}$ and Hachicha $\mathrm{M}$ : Neonatal purulent meningitis in southern Tunisia: Epidemiology, bacteriology, risk factors and prognosis. Fetal Pediatr Pathol 34: 233-240, 2015.

9. Softić I, Tahirović H and Hasanhodžić M: Neonatal bacterial meningitis: Results from a cross-sectional hospital based study. Acta Med Acad 44: 117-123, 2015.

10. Masand R, Ali A and Purohit A: Neonatal brain abscess: An atypical presentation. J Pediatr Neurosci 10: 282-284, 2015.

11. de Oliveira RS, Pinho VF, Madureira JF and Machado HR: Brain abscess in a neonate: An unusual presentation. Childs Nerv Syst 23: 139-142, 2007.

12. Leppert D, Leib SL, Grygar C, Miller KM, Schaad UB and Holländer GA: Matrix metalloproteinase (MMP)-8 and MMP-9 in cerebrospinal fluid during bacterial meningitis: Association with blood-brain barrier damage and neurological sequelae. Clin Infect Dis 31: 80-84, 2000.

13. Sellner J and Leib SL: In bacterial meningitis cortical brain damage is associated with changes in parenchymal MMP-9/TIMP-1 ratio and increased collagen type IV degradation. Neurobiol Dis 21: 647-656, 2006.

14. Hu R, Gong Y and Wang Y: Relationship of serum procalcitonin levels to severity and prognosis in pediatric bacterial meningitis. Clin Pediatr (Phila) 54: 1141-1144, 2015.

15. Henry BM, Roy J, Ramakrishnan PK, Vikse J, Tomaszewski KA and Walocha JA: Procalcitonin as a serum biomarker for differentiation of bacterial meningitis from viral meningitis in children: Evidence from a meta-analysis. Clin Pediatr (Phila) 55: 749-764, 2016.

16. Wei TT, Hu ZD, Qin BD, Ma N, Tang QQ, Wang LL, Zhou L and Zhong RQ: Diagnostic accuracy of procalcitonin in bacterial meningitis versus nonbacterial meningitis: A systematic review and meta-analysis. Medicine (Baltimore) 95: e3079, 2016.

17. Gaschignard J, Levy C, Romain O, Cohen R, Bingen E, Aujard Y and Boileau P: Neonatal bacterial meningitis: 444 cases in 7 years. Pediatr Infect Dis J 30: 212-217, 2011.

18. Adeboye MA, Obasa TO, Fadeyi A, Adesiyun OO and Mokuolu OA: Haemophilus meningitis in an African neonate: Time for active surveillance and institution of appropriate control measure. West Afr J Med 29: 275-277, 2010.

19. Nunnari G, Gussio M, Pinzone MR, Martellotta F, Cosentino S, Cacopardo B and Celesia BM: Cryptococcal meningitis in an HIV-1-infected person: Relapses or IRIS? Case report and review of the literature. Eur Rev Med Pharmacol Sci 17: 1555-1559, 2013.

20. Yang AP, Liu J, Yue LH, Wang HQ, Yang WJ and Yang GH: Neutrophil CD64 combined with PCT, CRP and WBC improves the sensitivity for the early diagnosis of neonatal sepsis. Clin Chem Lab Med 54: 345-351, 2016.

This work is licensed under a Creative Commons Attribution-NonCommercial-NoDerivatives 4.0 International (CC BY-NC-ND 4.0) License. 